Supplement of Nat. Hazards Earth Syst. Sci., 20, 1941-1953, 2020

https://doi.org/10.5194/nhess-20-1941-2020-supplement

(C) Author(s) 2020. This work is distributed under

the Creative Commons Attribution 4.0 License.

(c) (1)

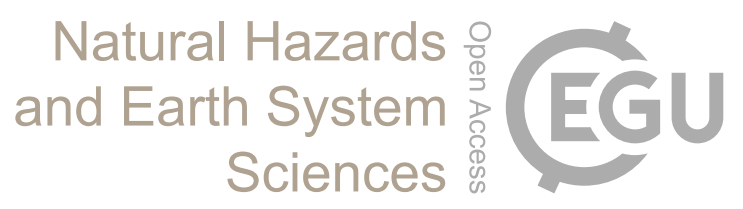

Supplement of

\title{
On snow stability interpretation of extended column test results
}

Frank Techel et al.

Correspondence to: Frank Techel (techel@slf.ch)

The copyright of individual parts of the supplement might differ from the CC BY 4.0 License. 
We also explored a sampling approach using an 80-20 ratio. The resulting splits were very similar as can be seen in Fig. 1 . The most notable difference in the splitting criteria were noted for the class threshold between classes 3 and 4 . Here, the first splits differed (ECTN $\leq 10$ vs. ECTN $\leq 3$ ). However, the second most frequent split obtained with $80 \%$ of the data $(E C T N \leq 10)$ was the same as the most frequent split obtained with $90 \%$ of the data. - Note there is a mistake in the manuscript on line 260 which should read: ECTP $\leq 14$ (48\%), ECTP $\leq 13$ (36\%) rather than ECTP $\leq 15$ (48\%), ECTP $\leq 14$ (36\%).

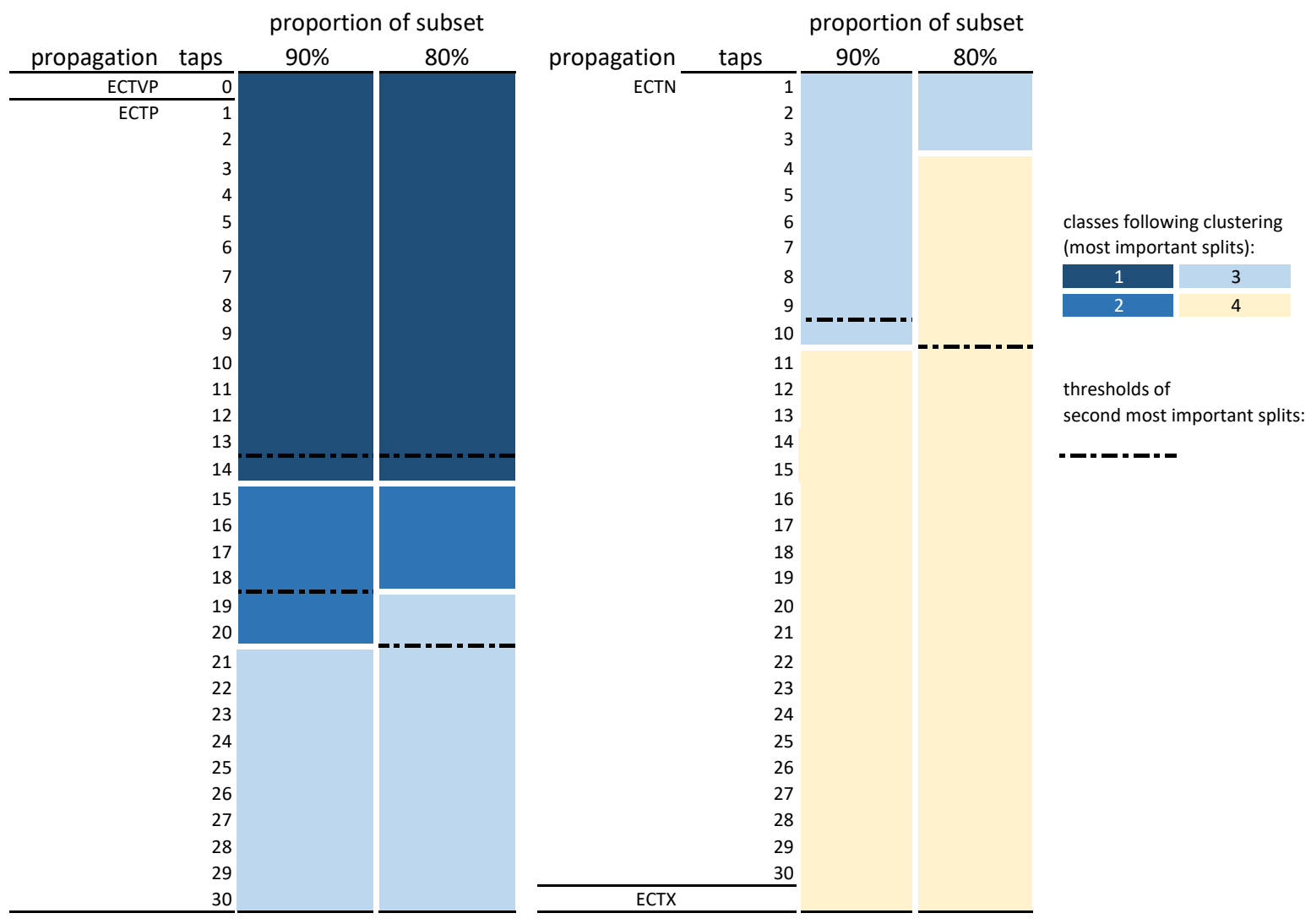

Figure S1. Clustering thresholds obtained, when using either $90 \%$ (currently used in the manuscript) or $80 \%$ of the data for each of the 100 repetitions. Colours represent the four classes based on the most frequently indicated splitting criteria. The dotted-dashed lines indicate the second most frequent splitting criteria. In general, the splitting criteria were rather similar. 